\title{
Effective and safe pharmacotherapy for pediatric population: a call for academia to conduct clinical research
}

\author{
Melva Louisa
}

Departement of Pharmacology and Therapeutics, Faculty of Medicine, Universitas Indonesia, Jakarta, Indonesia

Children are not small adults. Developmental changes in pediatric populations greatly affect their response to medicines. As children and adults differ in physiological maturity, it is necessary to realize that both populations differ in terms of pharmacokinetic profiles and pharmacodynamic characteristics. Diseases in children also might have different pathogenesis and they might also have a unique disease pattern as compared to adults. ${ }^{1-3}$

Prescribing in children mostly based on adult doses, or what might be worse, comes from adult guidelines, due to the lack of pediatric data. Many of the use of drugs in children, in particular for neonates and infants are off-label. ${ }^{4}$ The use of medicines based on adult data only can be unpredictable and sometimes might cause detrimental effects, such as Gray baby syndrome with chloramphenicol, Reye syndrome with aspirin, or enamel dysplasia with tetracycline. ${ }^{2}$ Pediatric population deserves medicines that have been proven safe and effective. However, pediatric patients are hardly ever represented in clinical research. ${ }^{1}$

One of the main reasons for the lack of data in a pediatric population is the reluctance to conduct studies in children due to ethical concerns and commercial reasons. ${ }^{4}$ Pharmaceutical companies tend to sponsor studies in adults than children. Cohen et $\mathrm{al}^{5}$ showed that in a 20-year period, the number of randomized clinical trials in adults has doubled in amounts, while the number of pediatric trials has been constant. Trials in children substantially increase cost, more complex, not to mention the more restriction and supervision from ethical committees and regulatory bodies. Many ethics committees can be over-protective due to lack of realization of the need for clinical trials in children, despite the advocacy for trials in children from the International Conference on Harmonization (ICH) E11. ICH E11 addressed the need for pediatric trials and protection for the children's welfare. ${ }^{6}$ Children are still considered as vulnerable subjects. There is also the reluctance from parents and families to contribute to clinical research. ${ }^{2}$

Here are where the academia initiatives for clinical research in a pediatric population is greatly needed. Leadership from academia is required to provide awareness to all pediatric stakeholders. Academia can start with clinical networks and provides direction to conduct good clinical research practice, particularly in children. Pediatric research can begin in medicine that mainly affect children. While carrying out research, all efforts should be made to minimize risks, which include all harms, privacy, and confidentiality. ${ }^{3}$ Children are indeed potentially vulnerable population, therefore, the safety monitoring committee should be established to foresee that the children are closely monitored. ${ }^{2,3}$ Informed consent from the parents or legal guardian, and informed assent from the children aged 7-18 years-old should be obtained to ensure that the subjects have agreed to participate and their rights have been protected. ${ }^{3}$ Lastly, scientific integrity is a fundamental issue. Academia is the key for the conduct of a scientifically sound and significant pediatric trials by providing a good study design. ${ }^{3}$

Two clinical research that involved pediatric populations are discussed in the present volume: a cohort study for early use of mannitol in pediatric intensive care unit, ${ }^{7}$ and a clinical trial of new regimen of albendazole in soiltransmitted helminths (STH) infection. ${ }^{8}$ The two studies provide data to support the effectiveness and safety of the respective drugs in diseases that greatly affects children. 
More studies in pediatric populations, especially the high-quality ones, are urgently needed. Further fruitful collaborations between academia, industry, patient, and families are required for the support of safe and effective use of medicines in pediatric populations.

\section{REFERENCES}

1. Stephenson T. How children's responses to drugs differ from adults. Br J Clin Pharmacol. 2005;59(6):670-3.

2. Joseph PD, Craig JC, Caldwell PH. Clinical trials in children. Br J Clin Pharmacol. 2013;79(3):357-69.

3. Badvekar SB. Pediatric clinical trials. Perspect Clin Res. 2013;4(1):89-99.

4. Ferro A. Paediatric prescribing: why children are not small adults. Br J Clin Pharmacol. 2014;79(3):351-3.

5. Cohen E, Uleryk E, Jasuja M, Parkin PC. An absence of pediatric randomized controlled trials in general medical journals, 1985-2004. J Clin Epidemiol. 2007;60(2):118-23.

6. The European Agency for the Evaluation of Medicinal Products (EMA). Evaluation of medicines for human use. ICH Topic E11. Clinical Investigation of Medicinal Products in the Pediatric Population. CPMP/ ICH/2711.99. 2000:1-12.

7. Sekarningrum PA, Wati DK, Suwarba IM, Hartawan IN, Mahalini DS, Suparyatha IBG. Early mannitol administration improves clinical outcomes of patients with brain edema. Med J Indones. 2018;27:244-9.

8. Sungkar S, Tambunan FB, Gozali MN, Kusumowidagdo G, Wahdini S. The effect of albendazole toward anemia in children with soil-transmitted helmints infection in a remote and endemic area. Med J Indones. 2018;27:293-8.

pISSN: 0853-1773•eISSN: 2252-8083•https://doi.org/10.13181/mji.v27i4.3428・Med J Indones. 2018;27:221-2 